REVISTA DE DERECHO UNED, NÚM. 18, 2016

\title{
INMIGRACIÓN, ASILO Y REFUGIO ANTE LOS RETOS ACTUALES DE LA POLÍTICA EXTERIOR EUROPEA*
}

\section{IMMIGRATION, ASYLUM AND REFUGE TO THE CURRENT CHALLENGES OF EUROPEAN FOREIGN POLICY}

Juan Manuel Goig Martínez**

Resumen: La necesidad de adoptar una política común en materia migratoria, de asilo y refugio, determinada en los Tratados, y exigida reiteradamente, no ha sido adoptada todavía en la Unión Europea, debido a las reticencias que los diversos Estados miembros han mostrado, en defensa de su propia soberanía, y también como consecuencia de las diferencias migratorias en los propios Estados. Ante la actual crisis de refugiados, y ante el terrorismo yihadista, la Unión Europea no ha asumido una política exterior migratoria adecuada, que haga de la garantía de los derechos de los inmigrantes y de los solicitantes de asilo y refugio su objetivo principal, y que facilite la aplicación del Derecho Internacional sobre la materia, sin menoscabo del ámbito de libertades de que son titulares los solicitantes de protección internacional y los inmigrantes.

Abstract: The need to adopt a common policy on migration, asylum and refugees, determined by the treaties, and demanded repeatedly, not has been adopted yet in the European Union, because of the reluctance that various Member States have shown, in defense of its own sovereignty, and also as a consequence of the migratory differen-

"Este artículo reproduce, solo en parte el artículo: ¿Una política común de inmigración en la Unión Europea? Evolución, retos y realidades, publicado en RDUE, número 29. Incluye la regulación del asilo, y las últimas novedades normativas hasta la publicación de este artículo.

${ }_{* * *}$ Profesor Titular de Universidad. UNED. Departamento de Derecho Político: juanmgoig@der.uned.es 
ces in the Member States. Before the current refugee crisis, and jihadist terrorism, the European Union has not taken a proper immigration foreign policy, making its main objective the guarantee of the rights of immigrants and asylum -seekers, and to facilitate the application of international law on the matter, without prejudice to the scope of freedoms that are applicants for international protection and migrants.

Palabras clave: inmigración, asilo, refugio, derechos de los inmigrantes, política migratoria común europea.

Keywords: immigration, asylum, refuge, immigrants'rights, European common immigration policy.

Recepción original: 10/02/2016

Aceptación original: 6/04/2016

Sumario: 1. Introducción. 2. Orígenes y desarrollo de una política común migratoria. De tampere a la política de integración. 3. Ciudadanía y protección de derechos en materia migratoria. 4. Realidad y actualidad de la política migratoria común: crisis de los refugiados y terrorismo yihadista. 4.1. Los Estados miembros ante la situación actual en inmigración. Derechos de los inmigrantes en la UE. 4.2. La política de la UE en materia de asilo y refugio. Entre el control de fronteras y la limitación de derechos.

\section{INTRODUCCIÓN}

La inmigración es un fenómeno en expansión que afecta a todos los países de la UE, aunque sus dimensiones, la intensidad de los flujos, las formas de llegada al país y las características de los inmigrantes presentan diferencias en cada uno de los Estados miembros.

Como ha indicado DE LUCAS ${ }^{1}$, en la UE parece haberse generalizado un modelo de gestión de la inmigración caracterizado por una política instrumental y defensiva, una política de policía de fronteras y adecuación coyuntural a las necesidades del mercado de trabajo, que no se ha centrado en el inmigrante y en su proyecto vital, al que se le imponen condiciones forzadas a la hora de reconocerles derechos y libertades, y que extranjeriza al inmigrante y estigmatiza la distinción entre el inmigrante necesario laboralmente, y los demás, y, de manera especial, al inmigrante en situación irregular, y que evade sus obligaciones en materia de asilo y refugio.

${ }^{1}$ DE LUCAS, J. «Algunas propuestas para comenzar a hablar en serio de política de inmigración» en Inmigrantes, ¿cómo los vemos? Algunos desafíos y malas respuestas, DE LUCAS, J. y TORRES, F (Dirs.), Madrid, Talasa, 2002, pág. 26. 
La delimitación del espacio de libertad, seguridad y justicia ha implicado la eliminación de las fronteras interiores de los Estados miembros, de modo tal que el control de las personas se ha trasladado a las fronteras exteriores ${ }^{2}$. Por esta razón las instituciones comunitarias han adoptado progresivamente medidas orientadas a mejorar el control de las personas en el cruce de las fronteras exteriores ${ }^{3}$.

El camino hacia una política europea común en materia de inmigración no se ha completado. Esta política de inmigración se encuadra, inicialmente, en el marco de la libre circulación de personas, tanto en su vertiente ad extra, respecto a los nacionales de terceros países, como en su visión ad intra en relación a los nacionales de los Estados miembros. El objetivo de la libre circulación de personas, que nace con el Acta Única Europea, se deja, sin embargo, en su vertiente exterior, como competencia básica de los Estados miembros. Esta situación cambia a partir del Consejo Europeo de Tampere que pone de manifiesto la necesaria labor armonizadora en materia de admisión y residencia de nacionales de terceros Estados, y de eficaz gestión de los flujos migratorios.

Pero junto a esta política, existe otra, consistente en la necesidad de ofrecer un trato justo a los inmigrantes, y en esta idea, la UE ha manifestado la existencia de dos principios esenciales que parten de la consideración positiva de la inmigración, elemento decisivo para evitar que surjan determinados peligros no deseados: por un lado la necesaria integración de los inmigrantes, y por otro, e íntimamente relacionado con el primero, el ámbito de derechos a otorgar a los inmigrantes, y que, inicialmente, se sitúa en la idea de acercar el estatus en materia de derechos a los de los ciudadanos de la UE, en base a dos condicionamientos esenciales: otorgar a los inmigrantes un permiso de residencia de larga duración y un permiso de trabajo permanente a las personas que han residido un número determinado de años en la Unión, creando una situación de residencia que implicaría unos derechos que se inspiran en los de los ciudadanos de los Estados miembros, puesto que el principio de igualdad constituye principio inspirador del Derecho Comunitario, pero que, en realidad, se limita a los derechos «sociales» y no incluyen los derechos políticos ${ }^{4}$.

${ }^{2}$ Vid. PERAL. L. «Límites jurídicos al discurso político sobre el control de flujos migratorios: non refoulement, protección en la región de origen y cierre de fronteras europeas», Revista Electrónica de Estudios Internacionales, n. ${ }^{\circ}$ 11, 2006.

${ }^{3}$ OLESTI RAYO, A. «La Unión Europea y la progresiva creación de un régimen comunitario de extranjería», en Revista catalana de Dret públic, núm. 40, 2010, págs. 7 y ss.

${ }^{4}$ IZQUIERDO, C, y TORRECUADRADA, S. «La regulación internacional de los flujos migratorios» en Ciudadanía e Inmigración, Zaragoza, Revista Aragonesa de Administración Pública, serie Monografías, n. ${ }^{\circ}$ VI, 2003, págs. 52 y 54. 


\section{ORÍGENES Y DESARROLLO DE UNA POLÍTICA COMÚN MIGRATORIA. DE TAMPERE A LA POLÍTICA DE INTEGRACIÓN}

En la actualidad, uno de los objetivos fundamentales de la Unión Europea es contar con una política de migración europea completa, con visión de futuro y basada en la solidaridad. La política de migración tiene por objeto establecer un enfoque equilibrado para abordar, tanto la migración regular, como la irregular. Ahora bien, si en la actualidad esto es aceptado no siempre ha sido así en el ámbito comunitario, y el camino para llegar a esta política común ha sido largo y no exento de tensiones.

Uno de los rasgos que ha caracterizado la política comunitaria sobre migraciones ha sido la postura anárquica, dispersa y defensiva que la Unión Europea ha adoptado en materia de procesos migratorios, puesto que ha constituido uno de los puntos de resistencia en el que con mayor fuerza se ha manifestado la tendencia de los Estados a salvaguardar su propia soberanía ${ }^{5}$, considerando las políticas migratorias competencias internas de los Estados ${ }^{6}$.

Desde 1998, en distintos Consejos europeos se hace referencia expresa a la inmigración. Ya en el Consejo Europeo de Viena de 1998, los Estados miembros habían apoyado un plan de acción específico sobre las modalidades óptimas para poner en marcha las disposiciones del Tratado de Ámsterdam relativas al establecimiento del «Espacio de Libertad, Seguridad y Justicia», prestando especial interés en la definición de una estrategia global relativa a los fenómenos migratorios.

Sin embargo el paso más importante en materia de política común de inmigración se manifiesta en las Conclusiones del Consejo Europeo de Tampere, que determina una necesaria política común en materia de asilo e inmigración basada en los siguientes principios:

1. Colaboración con los países de origen

2. Establecimiento de un sistema europeo común de asilo.

${ }^{5}$ MERCADER URQUINA, J. R, y MUÑOZ RUIZ, A. B. «El tratamiento de la política migratoria de la Unión Europea» en Revista del Ministerio de Trabajo y Asuntos Sociales, n. ${ }^{\circ} 32,20001$, págs. 36-37.

${ }^{6}$ Esta situación dispar fue parcialmente remediada por vía de acuerdos de emigración en los que, junto a las disposiciones tradicionales sobre las necesidades cualitativas y cuantitativas en mano de obra inmigrante; las condiciones de edad o de conocimiento, etc., se fueron añadiendo reglas sobre la reagrupación familiar, la formación profesional y otras medidas de cooperación. ORTÍZ-ARCE DE LA FUENTE, A. «Los extranjeros no comunitarios ante el Derecho Comunitario Europeo» en VV. AA. Derecho de extranjería, asilo y refugio, Ministerio de Asuntos Sociales, 1995. 
3. Gestión de los flujos migratorios, incluyendo la reagrupación familiar.

4. Trato justo a los nacionales de terceros países.

En noviembre de 2000, la Comisión publica su Comunicación al Parlamento y al Consejo sobre la política comunitaria de inmigración (COM (2000) 757), en la que se explicitaban los proyectos de acción concretos en que se deberían traducir las directrices de Tampere en relación a los cuatro pilares básicos de la política de inmigración.

A partir de este momento, se producen una serie de acciones dirigidas a favorecer el principio constitutivo de trato justo.

Con Lisboa se refuerza la idea de que la UE tiene como objetivo establecer un enfoque equilibrado para abordar la migración legal y luchar contra la inmigración ilegal. Una gestión apropiada de los flujos migratorios exige garantizar un trato equitativo de los nacionales de terceros países que residan legalmente en los Estados miembros, mejorar las medidas de lucha contra la inmigración ilegal y fomentar la cooperación con terceros países en todos los campos. La UE pretende desarrollar un nivel uniforme de derechos y obligaciones de los inmigrantes legales comparable al de los ciudadanos de la Unión.

A pesar de las dificultades que existen en la actualidad, en el Tratado de Lisboa se crean los fundamentos sobre los que será necesario desarrollar una política común de asilo, inmigración y control de fronteras exteriores, apelando a la solidaridad interestatal y al trato equitativo a los nacionales de los terceros Estados ${ }^{7}$. La desaparición de las estructuras de cooperación intergubernamental y la instauración de una única organización internacional que recoja las competencias y poderes que estaban distribuidos en los tres pilares, facilita y redimensiona el desarrollo de una verdadera política de inmigración común ${ }^{8}$.

Lisboa ha avanzado en la configuración de un estatuto jurídico europeo que regule los derechos y las obligaciones aplicables a los extranjeros, las condiciones para ejercer la reagrupación familiar o el contenido del estatuto del residente de larga duración. Sin embargo, la reserva estatal prevista en el TFUE que reconoce el derecho de los países miembros a determinar el volumen de extranjeros que pueden

${ }^{7}$ OLESTI RAYO, A. «La Unión Europea y la progresiva creación de un régimen comunitario de extranjería», en Revista catalana de Dret públic, núm. 40, 2010, pág. 5.

${ }^{8}$ Vid. DEL VALLE GÁLVEZ, A. "Inmigración, extranjería y fronteras en la Unión Europea. Cinco problemas conceptuales», Fronteras exteriores de la UE e inmigración a España: Relaciones internacionales y derecho, Cuadernos de la Escuela Diplomática, n. ${ }^{\circ}$ 33, Tirant lo Blanch, 2007, Valencia. 
admitir en su territorio, viene a romper la tendencia paulatina para la definición de una política europea común capaz de proporcionar un marco flexible que teniendo en cuenta las situaciones particulares de los países de la Unión Europea, se pueda aplicar de forma conjunta por los países miembros, y que debe basarse en los principios de solidaridad, confianza mutua, transparencia, responsabilidad y esfuerzos conjuntos de la UE y de sus países.

La integración ha adquirido un perfil importante en los debates políticos europeos, puesto que constituye un aspecto clave en cualquier debate sobre inmigración. Sin embargo estas cuestiones sobre integración se alejan de la igualdad y la variedad, para centrarse en la seguridad, lo que constituye un importante error. La integración es algo más importante que la inserción social, y elaborar una política de integración eficaz debe plantearse cuestiones en diversas áreas políticas y garantizar derechos, la igualdad de trato, la no discriminación, la naturalización y la ciudadanía.

La integración de los inmigrantes en Europa no ha tenido demasiado éxito hasta la fecha. El mandato de la UE para promover la integración emana de los Tratados Constitutivos, los Programas plurianuales del Consejo Europeo, y la Estrategia de los Tratados de 2020.

El Tratado de Lisboa proporciona, por primera vez, una base jurídica para la promoción de la integración en la Unión Europea: el artículo 79.4 estipula que el Parlamento Europeo y del Consejo podrán establecer medidas para alentar y apoyar la acción de los Estados miembros para promover la integración de nacionales de terceros países que residan legalmente en su territorio, con exclusión de toda armonización de las leyes y reglamentos de los Estados miembros».

En lo que respecta a los Programas plurianuales del Consejo Europeo, en el Consejo Europeo de Tampere, los líderes de la Unión Europea reclamaron el desarrollo de una política común en materia de inmigración, que incluyera medidas más dinámicas para la integración de nacionales de terceros países residentes en la Unión Europea, y acordaron que el objetivo de esta política de integración era conceder a los nacionales de terceros países de los derechos y obligaciones comparables a los de los ciudadanos de la UE.

La integración efectiva y responsable de los inmigrantes constituye un importante factor para lograr los objetivos de Lisboa. La Comisión fomenta y respalda los esfuerzos de los Estados miembros en materia de empleo, asuntos sociales e igualdad de oportunidades, haciendo hincapié en las cuestiones de género para aprovechar plena- 
mente el potencial de las mujeres inmigrantes en el mercado laboral. La promoción de los derechos fundamentales, la ausencia de discriminación y la igualdad de oportunidades para todos, son elementos clave de la integración.

\section{CIUDADANÍA Y PROTECCIÓN DE DERECHOS EN MATERIA MIGRATORIA}

La migración se ve influida por una combinación de factores económicos, políticos y sociales, tanto en el país de origen del emigrante (factores de incitación) como en el país de destino (factores de atracción), y la relativa prosperidad económica y estabilidad política de la UE han ejercido un efecto de atracción considerable sobre los inmigrantes

Desde 1950, Europa no ha dejado de ser receptor de inmigración. El comportamiento migratorio de los países miembros es, sin embargo, heterogéneo: la zona norte (Irlanda, Reino Unido, Finlandia y Suecia) ha sido muy dinámica en cuanto a movimientos migratorios; la zona central (Bélgica, Dinamarca, Alemania, Francia, Luxemburgo, Holanda y Austria) es el principal foco de atracción de la inmigración que se dirige a Europa; la zona mediterránea (Italia, España ${ }^{9}$, Portugal y Grecia) ha experimentado un cambio radical, dado que ha pasado de ser proveedora de emigrantes de la zona central a ser receptora de inmigrantes procedentes de África.

Dos cuestiones, íntimamente relacionadas, es preciso tratar cuando nos cuestionamos la política migratoria de la UE. Una primera referida al tratamiento de los derechos y libertades de los nacionales de terceros países, caracterizada por la concepción de la ciudadanía comunitaria. La otra, está marcada por el momento actual que vive Europa.

${ }^{9}$ El número de extranjeros con certificado de registro o tarjeta de residencia en vigor se sitúa en 4.933.231 personas, según la Estadística de Extranjeros residentes en España a 30 de junio de 2015 elaborada por el Observatorio Permanente de la Inmigración (OPI) de la secretaría general de Inmigración y Emigración. Del total de residentes extranjeros, 2.823.048 corresponden al régimen de libre circulación UE (ciudadanos UE y familiares nacionales de terceros países), es decir, el 57,23\% del total y 2.110 .183 al régimen general, el $42,77 \%$. Con respecto a 31 de diciembre de 2014, el número de extranjeros con certificado de registro o tarjeta de residencia en vigor ha aumentado en 8.142 , lo que supone un incremento del $0,17 \%$. Este aumento del número total de extranjeros residentes se debe al incremento de un $1,78 \%$ de los extranjeros en Régimen de Libre circulación UE y a un descenso del 1,92\% de los extranjeros en Régimen General. 
En lo que a la primera cuestión se refiere, con independencia del avance que Tampere implica en el desarrollo de una Política Comunitaria de inmigración, se ha perdido una gran oportunidad de que esta política común se dirigiera de una manera más eficaz a dar cumplimiento a los tres pilares básicos-Democracia, Derechos humanos y Desarrollo- necesarios para dar efectividad a cualquier política de inmigración que se situé en el contexto de la globalización ${ }^{10}$.

La equiparación de derechos, libertades y deberes de los nacionales de terceros países respecto a los ciudadanos de la Unión Europea para incrementar la integración se refiere a los inmigrantes que residen legalmente en la UE. Se favorece la lucha contra la inmigración irregular, beneficiando el establecimiento de instrumentos que agilicen la resolución y ejecución de la expulsión de inmigrantes irregulares, y haciendo de la lucha contra la irregularidad migratoria un asunto casi interno de los Estados miembros que ha llevado a la adopción de medidas dispares destinadas a reforzar los controles de identificación; hacer más rigurosas las condiciones para la expedición de visados y de permisos de estancia y trabajo; penalizando la ayuda a la inmigración irregular, y lo que es más grave, privándoles del ejercicio de derechos humanos ${ }^{11}$.

Entre las consideraciones que caracterizan la política comunitaria en materia de derechos y libertades de los inmigrantes, existe una que es la clave de dicha política y es que no podemos olvidar que la concepción de ciudadanía de la $\mathrm{UE}^{12}$ se vincula a las viejas concepciones del Estado/nación y de la nacionalidad, y se concibe en un sentido complementario, que no sustitutivo, de la ciudadanía nacional.

Sin embargo, la noción de ciudadanía está siendo objeto de una importante revisión producida por factores ligados a la transformación de la sociedad contemporánea y por la aparición de diferentes revisiones de su significado y de su papel en las democracias liberales. La quiebra del concepto tradicional de ciudadanía obedece a una se-

${ }^{10}$ DE LUCAS, J. «Las propuestas sobre políticas de inmigración en Europa y la nueva Ley 4/2000 en España», en COLOMER VIADEL, A (Coord.), Emigrantes y estabilidad en el Mediterráneo. La polémica Ley de extranjería, Madrid, Poder, Ed. Nomos, 2001 pág. 150 (nota 13).

${ }^{11}$ MERCADER URQUINA, J. R, y MUÑOZ RUIZ, A. B. "El tratamiento de la política migratoria de la Unión Europea» en Revista del Ministerio de Trabajo y Asuntos Sociales, n. ${ }^{\circ} 32,2001$ pág. 62.

${ }^{12}$ Esta noción de ciudadanía irrumpe en el derecho de la Unión Europea en los arts. 8 y 8A a 8E del TCE en su versión de Maastricht de 1992. El TCE, en la redacción dada en Ámsterdam, lo regula, con alguna modificación respecto a la originaria, en sus artículos 17 a 22. La Cumbre de Niza introduce en el actual art. 18 TCE algunas limitaciones en aspectos relativos a la libre circulación. 
rie de factores entre los que se destacan la crisis del Estado social, la emergencia de sociedades multiculturales, y la mundialización, y en este contexto no es el de menor importancia el aumento y los cambios en los flujos migratorios, de manera tal que se debería llegar a la elaboración de un modelo de ciudadanía universal cuyo anclaje debieran ser los Tratados Internacionales universales en materia de derechos y libertades y que se basase en el carácter universal de los derechos en ellos proclamados ${ }^{13}$.

En el Consejo Europeo de Sevilla de 2002, se puso de manifiesto la necesidad de un equilibrio entre tres políticas: a) la integración de los inmigrantes en situación regular; b) una política europea de asilo, y c) una posición común en materia de inmigración irregular, como pieza clave de la actuación de la UE en materia de inmigración.

Pero la construcción de una ciudadanía europea que fije un estatuto para los inmigrantes caracterizado por el reconocimiento de derechos fundamentales no es la que se ha impuesto en la UE desde el Tratado de Maastricht, sino que se opta por una consideración de la ciudadanía que tiende a separar perfectamente el estatus entre los nacionales de Estados miembros y los nacionales de Estados terceros, de manera especial en materia de derechos y libertades.

Como ha indicado MIRALLES SANGRO ${ }^{14}$, la noción de ciudadanía de la UE debe impulsarse hacia una dinámica jurídica, política, social y económica que permita hacer realidad el principio de no discriminación por razón de la nacionalidad y otras condiciones, y hacia la perspectiva universalizadora de los derechos humanos sobre los que se construye el edificio de la UE. Si las menciones que el Derecho Comunitario hace de los derechos humanos y de las libertades públicas debe de orientarse en relación a una perspectiva que sea conciliable con la visión solidaria y universalista de los mismos, el espacio de libertad, seguridad y justicia, como uno de los pilares comunitarios, no puede seguir centrándose solamente sobre la base del reforzamiento de las fronteras externas ni sobre la discriminación y limitación en sus derechos a los inmigrantes ${ }^{15}$, pues se corre el riesgo de chocar frontalmente

${ }^{13}$ MARTÍNEZ DE PISÓN CAVERO, J. «Ciudadanía e inmigración en las sociedades multiculturales» en Ciudadanía e inmigración. Óp. Cit. págs. 29 y ss.

${ }^{14}$ MIRALLES SANGRO, PP. «Presente y futuro de la ciudadanía de la Unión Europea» en Revista de Derecho de la Unión Europea, n. ${ }^{\circ}$ 1, 2. ${ }^{\circ}$ semestre, 2001, págs. 156 y 157.

${ }^{15}$ Una visión de la ciudadanía europea conciliable con la globalización democrática y solidaria puede consultarse en TRUYOL SERRA, A. La integración europea. Análisis histórico-institucional con textos y documentos. 1 Génesis y desarrollo de la CE, Madrid, Técnos, 1999. 
con las exigencias del Estado de Derecho y con el modelo de democracia plural e integradora. La amenaza que al Estado de Derecho implica la política comunitaria se observa en que no apuesta con claridad por el principio de igualdad de derechos entre ciudadano e inmigrantes residentes estables, y lo que es peor, porque regatean, e incluso niegan, el reconocimiento y garantía efectiva de derechos humanos fundamentales en función de una condición administrativa como es la irregularidad, que se usa como justificación de dicha exclusión.

En materia de derechos y libertades en la UE no se parte de la nada ${ }^{16}$, sino que, por el contrario, ya están sistematizados y desarrollados, existe una abundante jurisprudencia sobre derechos fundamentales, y las referencias en los Tratados son numerosas, y se ha partido de la CEDH, pero también de los principios constitucionales de sus miembros.

Estos planteamientos, referentes a derechos humanos, también tienen su plasmación en el art. 6.1 del Tratado de la Unión Europea, tras la reforma de Ámsterdam, al establecer que «la Unión se basa en los principios de libertad, democracia, respeto de los derechos humanos $y$ de las libertades fundamentales y el Estado de Derecho, principios que son comunes a los Estados miembros».

Tampoco podemos olvidar que la Carta de los Derechos Fundamentales de la Unión Europea manifiesta en su Preámbulo que «... la Unión está fundada sobre los valores indivisibles y universales de la dignidad humana, la libertad, la igualdad y la solidaridad, y se basa en los principios de la democracia y el Estado de Derecho», reconociendo en su artículo 1 que "La dignidad humana es inviolable. Será respetada y protegida» $^{17}$.

\section{REALIDAD Y ACTUALIDAD DE LA POLÍTICA MIGRATORIA COMÚN: CRISIS DE LOS REFUGIADOS Y TERRORISMO YIHADISTA}

Respecto a la segunda cuestión que planteábamos en líneas anteriores, en los últimos tiempos, terrorismo e inmigración ilegal amenazan

${ }^{16}$ Las sentencias del Tribunal Constitucional alemán Solange I de 1974, y Solange II de 1986, ya indicaron en su momento los derechos fundamentales de los ciudadanos de la UE, cuestionando, incluso, la primacía del derecho comunitario en Alemania en tanto no se ofreciera una garantía de derechos equiparable a la que ofrecía el ordenamiento alemán.

${ }^{17}$ RODRÍGUEZ BEREIJO, A. «La Carta de Derechos Fundamentales de la UE» en Revista de Derecho de la Unión Europea, n. ${ }^{\circ} 1$, 2. ${ }^{\circ}$ semestre, 2001, págs. 45 y ss. 
uno de los principios más importantes de la UE, la libre circulación, por lo que es preciso que nos planteemos la manera de gestionar la seguridad en las fronteras sin vulnerar los derechos y libertades de los inmigrantes, y sin traicionar los principios comunitarios.

Los recientes acontecimientos pueden propiciar situar en la misma posición la lucha contra el terrorismo, la política europea exterior común, en especial haca Oriente Próximo, el control de fronteras, la libertad de circulación, la lucha contra la inmigración irregular, y la integración de minorías de distinta cultura o religión en nuestras sociedades.

En 2015 se ha producido un aumento de inmigración irregular ${ }^{18}$, incrementada por diversos factores: la oleada de conflictos en Oriente Próximo (en especial los problemas en Libia y Siria); la presión demográfica en África; el aumento de tráfico ilegal de personas como consecuencia del desarrollo de mafias organizadas; la emigración económica procedente de los Balcanes, y las propias dificultades de la UE para gestionar de manera homogénea sus fronteras.

A ello hay que añadir el desafío del terrorismo yihadista, que puede exigir mayores controles internos y externos de nuestras fronteras, incluso la mejora de los instrumentos que ya existen como el Sistema de Información Shengen (SI-I y SIS-II) ${ }^{19}$, que desde 1995 permite compartir determinados datos, o el Sistema de Información Avanzada de Pasajeros (APIS), que es un registro de pasajeros al que se tiene acceso antes de que se realice el transporte aéreo, el sistema de Información de Visados (VIS), incluso se defiende la puesta en marcha del Archivo de Nombres de Pasajeros (PNR), registro con información relacionada con una reserva aérea en el que se detallan ciertos datos, siempre y cuando se respeten los derechos fundamen-

${ }^{18}$ Los últimos datos que ofrece FRONTEX, indican que más de 57.000 inmigrantes irregulares llegaron a Europa en el primer trimestre de 2015, cifra que triplica los datos del mismo período del año 2014.

${ }^{19}$ Reglamento (CE) n. ${ }^{\circ} 1104 / 2008$ del Consejo de 24 de octubre de 2008 sobre la migración del Sistema de Información de Schengen (SIS 1+) al Sistema de Información de Schengen de segunda generación (SIS II), y Decisión n. ${ }^{\circ}$ 2008/839/JAI del Consejo de 24 de octubre de 2008 sobre la migración del Sistema de Información de Schengen (SIS 1+) al Sistema de Información de Schengen de segunda generación (SIS II). (ACTOS CONEXOS: Informe de la Comisión al Parlamento Europeo y al Consejo, de 6 de mayo de 2010, sobre el desarrollo del sistema de información de Schengen de segunda generación (SIS II) - Informe de ejecución Julio 2009 - Diciembre 2009 [COM(2010) 221final - no publicado en el Diario Oficial], Informe de la Comisión al Consejo y al Parlamento Europeo, de 22 de octubre de 2009, sobre el desarrollo del sistema de información de Schengen de segunda generación (SIS II) Informe de ejecución Enero de 2009 - Junio de 2009 [COM(2009) 555 final - no publicado en el Diario Oficial]. 
tales implicados (especialmente el derecho a la intimidad personal, y la prohibición de discriminación $)^{20}$, pero lo que no tendría cabida, de acuerdo con las políticas comunitarias, sería la drástica alteración del espacio Shengen, puesto que constituye uno de los principios comunitarios básicos.

Es necesario potenciar una política exterior europea que, además de los principios de defensa y diplomacia, y de una adecuada política de asilo y refugio, desarrolle una acertada política de cooperación y desarrollo con nuestros vecinos, elemento indispensable para el desarrollo de una adecuada política migratoria.

Incluso son posibles restricciones temporales al espacio Shengen, en situaciones coyunturales, en la idea de que la cooperación se hace precisa, sin restringir la libertad de movimientos, y colaboración de la UE con determinados Estados miembros que sufren una mayor presión migratoria, con la consiguiente comprensión de otros Estados.

\subsection{Los Estados miembros ante la situación actual en inmigración. Derechos de los inmigrantes en la UE}

La situación actual, sin embargo, no es muy alentadora: Bélgica ya limita beneficios sociales a ciudadanos comunitarios, y Reino Unido pretende establecer limitaciones a dichos beneficios -incluso se ha propuesto la posible celebración de un referéndum sobre su permanencia en la UE-; Francia ha amenazado con endurecer los controles en el territorio Shengen; Alemania propone impedimentos a la libre circulación de nacionales de ciertos Estados de la UE; Suiza ha convocado un referéndum para limitar la inmigración europea, violando la relación de movimientos que rige desde 2002; Grecia amenaza con abrir sus fronteras para dejar paso a la inmigración que procede del sur, como medida de presión en la negociación de su rescate, y España - ha limitado derechos a inmigrantes en situación irregular, como el derecho a la sanidad, y ha legalizado el «rechazo en frontera» sin garantías-, e Italia, que sufren una presión migratoria muy fuerte, por ser fronteras exteriores, no pueden gestionar adecuadamente los flujos migratorios irregulares en sus territorios.

${ }^{20}$ La creación de bases de datos personales, con la finalidad de determinar perfiles étnicos y culturales-religiosos, plantea importantes objeciones a la hora de velar por el derecho a la no discriminación (art. 21 Carta de los Derechos Fundamentales de la UE). Cfr. DICTAMEN DEL COMITÉ ECONÓMICO Y SOCIAL EUROPEO (2009), de 4 de noviembre, sobre «El respeto de los derechos fundamentales en las políticas y la legislación europeas en materia de inmigración» (SOC/335-CESE 1710/2009). 
En materia de derechos sociales, el TJUE, ha determinado que «los ciudadanos de la UE económicamente inactivos que van a otro estado miembro exclusivamente para obtener ayuda social podrían ser excluidos de ciertos beneficios sociales», de manera que el Tribunal europeo no solo acota el acceso a las ayudas sociales en cualquier país de la UE, sino que también da respaldo a iniciativas restrictivas de lo que se denomina turismo de bienestar o turismo social. La sentencia TJUE de 11 de noviembre de 2014 (C-333/13), clarifica que la libre circulación no implica que se tenga automáticamente acceso a los sistemas sociales de los Estados miembros». No existe «un derecho a acceder libremente a los sistemas de asistencia social de los Estados miembros», por lo que la sentencia aporta más claridad sobre los derechos de los ciudadanos de la UE y sus familias respecto al acceso a los beneficios sociales cuando residen en otro Estado miembro.

En este mismo orden, Estados como Bélgica, Francia, Reino Unido, Dinamarca o España, solicitan la revisión y ajuste de los sistemas sociales para ciudadanos de Estados miembros, que incluyen conceptos como la introducción de planteamientos de temporalidad (limitar el tiempo de estancia en la prestación), la vinculación de las ayudas con la activación laboral y la participación en procesos de reinserción individual, el reforzamiento de los sistemas de control y sanción, la exigencia de contraprestación laboral (participación en trabajos de interés colectivo) y la limitación de la cuantía de las prestaciones. La mayor parte de los Estados limitan la protección a la población extranjera con residencia legal (Francia, Bélgica, Luxemburgo, Países Bajos, Suecia, Portugal, República Checa, Eslovaquia, Estonia) o, de forma aún más restrictiva, a la que dispone del derecho a la residencia legal permanente (Finlandia, Malta, Chipre, Eslovenia, Hungría, Polonia, Lituania, Letonia, Bulgaria). También orientadas en exclusiva a las personas con residencia legal, otras normativas se centran en la presencia en el territorio o la residencia habitual en él (Reino Unido o Irlanda).

Sin embargo, el último ámbito donde la UE debe de mantener su firmeza es el relativo a la libertad de circulación para mantener el proyecto político y ciudadano que ha desarrollado a lo largo de un proceso muy largo, porque la libre circulación de personas es un derecho fundamental que asiste a los ciudadanos de la UE en virtud de los Tratados ${ }^{21}$. La cooperación Schengen, como parte del marco jurí-

${ }^{21}$ La Directiva 2004/38/CE del Parlamento Europeo y del Consejo, de 29 de abril de 2004, relativa al derecho de los ciudadanos de la Unión y de los miembros de sus familias a circular y residir libremente en el territorio de los Estados miembros, modifica el Reglamento (CEE) n. ${ }^{\circ} 1612 / 68$ y deroga las Directivas 64/221/CEE, 
dico e institucional de la UE, se ha expandido paulatinamente hasta incluir a la mayoría de los Estados miembros y a algunos países extracomunitarios-, y se expresa a través del espacio de libertad, seguridad y justicia exento de fronteras internas. La supresión de las fronteras internas implica una gestión reforzada de las fronteras externas de la Unión así como la regularización de la entrada y la residencia de personas de países extracomunitarios a través de medidas como la política común de asilo e inmigración.

La cuarta dimensión substantiva del proyecto europeo se refiere a su papel como actor global en un sistema internacional caracterizado por rápidos e intensos procesos de cambio en la naturaleza, las fuentes y las pautas de distribución del poder. Solo a través de una acción exterior común, y en particular mediante la Política Exterior y de Seguridad Común (PESC), incluyendo la Política Común de Seguridad y Defensa (PCSD), se lograría que los Estados miembros y la UE como tal sigan siendo relevantes y puedan promover en el exterior tanto sus intereses como sus valores.

La perspectiva global e integrada para la política migratoria comunitaria planteada por la UE, y formalmente apoyada por los gobiernos de los Estados miembros, se está revelando, simplemente, como una declaración de principios. En realidad, en los últimos años, la UE ha demostrado una absoluta incapacidad para elaborar una política migratoria común, coherente y multidimensional: la gestión de la inmigración se sigue caracterizando más bien por la externalización de las fronteras comunitarias, la lucha contra la inmigración "no controlable», y la definición de estatus jurídicos distintos y discriminantes entre el colectivo migrante. Esta visión se manifiesta cada vez más incompleta y unilateral, además de insuficiente y equivocada. El control de las fronteras a cualquier precio está suponiendo la falta de criterios de transparencia, legalidad y humanidad, así como violaciones de la legalidad y de los Derechos Humanos de las personas migrantes ${ }^{22}$.

La realidad nos muestra que el control y vigilancia de fronteras sigue en manos de cada Estado; que FRONTEX apoya las labores de vigilancia pero no tiene medios suficientes, y que los países no fronterizos podrían limitar el espacio Schengen.

68/360/CEE, 72/194/CEE, 73/148/CEE, 75/34/CEE, 75/35/CEE, 90/364/CEE, 90/365/ CEE y 93/96/CEE.

${ }_{22} \mathrm{Vid}$. BAZZACO, E. «La Unión Europea frente a los procesos migratorios: lejos de una política integral», en Papeles, n. ${ }^{\circ}$ 104, 2008/2009. 
La migración es un fenómeno complejo y cambiante, y la UE debe asegurar que sus políticas migratorias protejan los beneficios que la inmigración puede conllevar para la UE y sus ciudadanos, así como para los inmigrantes mismos y sus países de origen. La inmigración no es algo que se haya de impedir, sino gestionar. El Programa de La Haya afirma que «la migración internacional continuará», y será cada vez más difícil para cualquier país gestionar en solitario con éxito este desafío cambiante, por lo que es necesario contemplar los asuntos migratorios de forma completa y coherente, a través de una adecuada Política Común en materia de Migración de la $\mathrm{UE}^{23}$.

Para adoptar un planteamiento global, debemos admitir que la inmigración legal es sólo una parte del fenómeno migratorio, de manera que para ser exhaustivos, la UE debe abordar también la inmigración ilegal. El control de las fronteras exteriores de la Unión Europea ha sido objeto de especial atención como resultado de la ampliación, la cuestión de la seguridad y el incremento de la presión migratoria, y en el interior de la Unión Europea hay que culminar la libertad de circulación para las personas en el Espacio Schengen. Pero el interés en la integración exige un tratamiento similar entre los crecientes desafíos sobre inmigración y seguridad. No puede haber inmigración sin integración, por lo que las políticas migratorias comunitarias deben respetar las diferentes tradiciones, culturas y religiones, mientras cumplan rigurosamente con las leyes nacionales y de la UE, y con absoluto respeto al valor de la vida y dignidad humana.

Pero el Tratado de Funcionamiento de la Unión Europea (TFUE) consolida la inmigración y el asilo como asuntos de seguridad interior del territorio de la UE, bajo la rúbrica «Espacio de libertad, seguridad y justicia» (Título V). Al amparo de esta cartera, se continúan gestionando los flujos migratorios a través de una política común de inmigración, asilo y control de las fronteras exteriores (art. 67.2 TFUE) basada, primordialmente, en la prevención y lucha «reforzada» contra la inmigración «ilegal» (art. 79.1 TFUE), como presupuesto del espacio de seguridad al que se aspira. La política inmigratoria de la UE concibe la lucha contra el inmigrante ilegal como baluarte estratégico de la primacía de la potestad de los Estados sobre el control del acceso y condiciones de permanencia de extranjeros en el territorio, eje principal de la política común y presupuesto

\footnotetext{
${ }^{23}$ FRATINNI, F. «La política de migración de la UE: del Programa de la Haya a los importantes logros actuales», en Europa en la encrucijada, Colección Mediterráneo Económico n. ${ }^{\circ}$ 12, de la Fundación Cajamar, 2009.
} 
para alcanzar un espacio de libertad, seguridad y justicia en el territorio de la UE (art. 67.2 TFUE) ${ }^{24}$

El Dictamen del Comité de las Regiones «Esfuerzos por fomentar una verdadera solidaridad mediante una auténtica política migratoria europea» (2015/C 019/12), de 21 de enero de 2015, recuerda que quince años después de los primeros intentos de elaborar una política migratoria común, persiste un gran desfase entre la práctica y los principios y valores comunitarios. No se ha recurrido suficientemente al artículo 80 del TFUE para adoptar medidas que materialicen la solidaridad y el reparto equitativo de responsabilidades en cuanto a la libre circulación, incluidas sus repercusiones financieras, entre Estados miembros. Los compromisos adoptados en materia de circulación, instalación y retorno se han hecho sobre una base voluntaria y considera que, en una cuestión tan delicada y estratégica, la UE y sus principales instituciones deberían configurar una verdadera política migratoria y asumir las responsabilidades políticas consiguientes en cuanto a su aplicación, sin dejar este papel a cada Estado, sobre todo en el caso de los Estados fronterizos.

La política de inmigración de la Unión Europea relativa al control y la gestión de los flujos migratorios puede abordarse desde múltiples perspectivas. Además de la dimensión económica, es necesaria la orientación defensiva que pone en evidencia la exigencia de blindar las fronteras ante la interpretación de la inmigración desde una visión de seguridad y orden público. Pero junto a ello, es preciso un enfoque social, que supere la pretendida homogeneidad europea que se toma como referencia en la articulación de esta política -esta política desde la perspectiva social viene marcada por el intento de proteger a los europeos frente a la invasión o a la posible desnaturalización consecuencia de la inmigración-, reconociendo derechos y libertades a los inmigrantes, en la medida en que sea constitucionalmente admisible, y en la necesidad de integración de los inmigrantes, concibiendo la integración en forma de derechos y obligaciones ${ }^{25}$.

La crisis económica y sus efectos sociales, y el terrorismo, están provocando que en la UE se apliquen políticas más restrictivas en materia migratoria y de asilo, llegando a poner en cuestión los valores

${ }^{24} \mathrm{Vid}$. POMARES CINTAS, E. «La Unión Europea ante la inmigración ilegal: la institucionalización del odio» Eunomía. Revista en Cultura de la Legalidad N. ${ }^{\circ}$, septiembre 2014-febrero 2015.

${ }^{25}$ Vid. SOLANES CORELLA, A. «La política de inmigración en la Unión Europea. Desde tres claves», en ARBOR, CLXXXI, 713, mayo-junio, 2005. 
fundacionales de la Unión y la letra del propio Tratado de Lisboa en materia de derechos humanos.

Una Europa basada en un enfoque pragmático y jurídico de la solidaridad y de la responsabilidad compartida debe esforzarse en adoptar y aplicar medidas orientadas a prevenir la inmigración irregular y crear rutas alternativas seguras y legales hacia Europa, con el fin de evitar más pérdidas de vidas humanas durante viajes peligrosos. Pero considerar la inmigración únicamente como un problema «de fronteras físicas» es optar por una perspectiva parcial. Es necesario tener en cuenta las otras fronteras y recordar que la solidaridad procede de la sensibilización: puesta en común de las mejores prácticas, informaciones y directrices comunes.

En realidad, la integración se basa en un difícil equilibrio entre dos actitudes o conductas: por un lado, quienes se instalan en nuestro país deben respetar las leyes vigentes y los principios y valores en los que se inspiran; por otro, hemos de aceptar sus diferencias culturales y religiosas salvo que vulneren la legislación, principios y valores a los que acabamos de referirnos. Parece una propuesta obvia, pero no es fácil ponerla en práctica.

El V Informe Anual de Migración y Asilo (2013) de la Comisión ${ }^{26}$ ha manifestado la necesidad de que la UE interviniera para ayudar a los Estados miembros a responder al reto de la presión migratoria, respetando plenamente los derechos fundamentales de los inmigrantes. La UE debe garantizar la seguridad de las fronteras de Europa con adecuados canales legales de entrada, pero también combatir la violencia y la discriminación contra inmigrantes, y fomentar activamente su integración.

La creación del Espacio de Libertad, Seguridad y Justicia contemplado en el Título V del Tratado de Funcionamiento de la Unión Europea (TFUE) exige el pleno respeto de los derechos fundamentales por parte de la UE y de todos los Estados miembros, y según el artículo 6 del TUE, la UE tiene la responsabilidad de respetar y hacer respetar los derechos fundamentales en todas sus acciones, independientemente de las competencias ${ }^{27}$.

${ }^{26}$ COMUNICACIÓN DE LA COMISIÓN AL PARLAMENTO EUROPEO Y AL CONSEJO, $\operatorname{COM}(2014)$, de 22 de mayo de 2014.

${ }^{27}$ Durante los últimos años, la actividad normativa de la UE en materia de derechos y libertades ha sido frecuente. Vid. entre otras: Comunicación de la Comisión sobre un nuevo marco de la UE para reforzar el Estado de Derecho (COM(2014)0158) y las conclusiones del Consejo de 16 de diciembre de 2014, tituladas «Garantizar el respeto del Estado de Derecho»; Informe de la Comisión sobre la aplicación de la Carta de los Derechos Fundamentales de la Unión Europea en 2013 (COM(2014)0224); 
El Proyecto de Informe sobre la situación de los derechos fundamentales en la UE (2013-2014) (2014/2254(INI), de 6 de abril de 2015) de la Comisión de Libertades Civiles, Justicia y Asuntos de Interior del Parlamento Europeo, en materia de «Migrantes y refugiados» condena la detención de migrantes irregulares, incluidos los menores no acompañados, con fines de expulsión, y pide a los Estados miembros el cumplimiento de las disposiciones de la Directiva sobre el retorno, lamenta la trágica y reiterada pérdida de vidas humanas en el Mediterráneo, y reitera la necesidad de hacer todo lo posible para salvar la vida de las personas en peligro; mejorar los canales legales para los refugiados e introducir nuevas formas de acceso legal.

Los últimos acontecimientos en el Mediterráneo, tanto en los naufragios procedentes del África Subsahariana frente a la costa española, y, sobre todo, en los naufragios de embarcaciones procedentes de Libia y Siria en las costas italianas, han puesto de manifiesto la necesidad de modificar los sistemas de control exterior, reconociendo a FRONTEX competencias en salvamento marítimo -con dotación de medios adecuados a las Operaciones de salvamento (las Operaciones «Mare Nostrum», «Tritón» y «Poseidón», han dado resultados, pero las dotaciones son insuficientes)-, pero, de manera especial, exigen la solidaridad de la UE con los Estados fronterizos, políticas de codesarrollo con los Estados de origen y de tránsito, la lucha contra las redes de tráfico de seres humanos, y la apuesta decidida por una política común e integral de la inmigración.

El Consejo Europeo extraordinario de abril de 2015 convocado para abordar el problema de la inmigración hacia Europa, cuyas conclusiones han sido insatisfactorias, ha servido para revelar la idea de reforzar la cooperación con los Estados africanos para atacar las causas de la inmigración ilegal, así como la necesidad de poner en marcha acuerdos con terceros países para favorecer la readmisión de inmigrantes económicos en situación irregular, todo ello en el contexto de una política común migratoria, que incluso trasciende las fronteras de la UE, puesto que se ha solicitado la intervención de la ONU para la lucha contra la trata de seres humanos. Pero también ha puesto de manifiesto la falta de solidaridad de los Estados de la UE que no

Informe de la Comisión sobre la ciudadanía de la UE 2013 - Ciudadanos de la Unión: vuestros derechos, vuestro futuro (COM(2013)0269); Dictamen 2/2013 del Tribunal de Justicia de la Unión Europea sobre el proyecto de acuerdo relativo a la adhesión de la UE al Convenio Europeo de Derechos Humanos; Directrices estratégicas para el espacio de libertad, seguridad y justicia adoptadas por el Consejo Europeo el 27 de junio de 2014; Conferencia anual de la Agencia Europea de los Derechos Fundamentales (FRA) de 10 de noviembre de 2014 sobre el tema «Los derechos fundamentales y la inmigración en la UE». 
se enfrentan a problemas de entrada de inmigrantes, que reducen sus actuaciones a aspectos puramente económicos y de control de fronteras, pero se abstienen de recibir un mayor volumen de inmigrantes, incluso cuando sean demandantes de asilo.

\subsection{La política de la UE en materia de asilo y refugio. Entre el control de fronteras y la limitación de derechos}

Respecto al establecimiento de un proceso común de asilo, el Sistema Europeo Común de Asilo (SECA) ha pretendido constituir máxima prioridad para la UE, y su instauración puede ser entendido, al menos en su aspecto teórico, como un éxito histórico, una meta a la que los Estados miembros de la Unión Europea (UE) y el Parlamento aspiraban desde 1999.

El SECA pretende facilitar el acceso al procedimiento de asilo a las personas necesitadas de protección; permitir la adopción de decisiones más justas, rápidas y acertadas; asegurar a quienes temen persecución que no se les devolverá a la situación de peligro; y, finalmente, ofrecer condiciones dignas y aceptables tanto a los solicitantes de asilo como a los beneficiarios de protección internacional dentro de la Unión.

En un espacio con fronteras abiertas y libertad de circulación, la UE debe aplicar un enfoque común a la política de asilo en toda la UE, puesto que el asilo es un derecho fundamental, y su concesión, una obligación internacional con arreglo a la Convención de Ginebra de 1951 sobre el Estatuto de los Refugiados.

Se ha acordado un nuevo paquete legislativo de la UE que fija un conjunto de rigurosas normas comunes y refuerza los procedimientos de cooperación para garantizar a los solicitantes de asilo igualdad de trato en un sistema justo y transparente, con independencia del lugar en que presenten su solicitud. Este complejo legislativo está integrado por diversas normas ${ }^{28}$ :

- La Directiva sobre procedimientos de asilo revisada ${ }^{29}$ pretende facilitar la adopción de decisiones más justas, rápidas y

${ }^{28}$ Un sistema Común de Asilo. Documento de la Comisión Europea. Oficina de publicaciones de la UE, Luxemburgo, 2014.

${ }^{29}$ Directiva 2005/85/CE del Consejo, de 1 de diciembre de 2005, sobre normas mínimas para los procedimientos que deben aplicar los Estados miembros para conceder o retirar la condición de refugiado. Modificada por Directiva 2013/32/UE del Parlamento Europeo y del Consejo, de 26 de junio de 2013, sobre procedimientos 
acertadas. Los solicitantes de asilo con necesidades especiales recibirán la asistencia necesaria para ofrecer las explicaciones que respaldan su demanda; se intensificará la protección de los menores no acompañados y de las víctimas de tortura.

- La Directiva sobre condiciones de acogida revisada ${ }^{30}$ garantiza la existencia de condiciones materiales de acogida humanitarias para los solicitantes de asilo en toda la UE y el total respeto de los derechos fundamentales de los interesados. Además, asegura que las medidas de detención solo se apliquen como último recurso

- La Directiva sobre requisitos revisada ${ }^{31}$ aclara los motivos que pueden dar lugar a protección internacional, con lo que fortalece las decisiones sobre asilo. Además, mejora el acceso de los beneficiarios de protección internacional a los derechos y las medidas de integración.

- El Reglamento de Dublín revisado ${ }^{32}$ refuerza la protección de los solicitantes de asilo durante el proceso de determinación del Estado responsable de examinar la solicitud y aclara las reglas por las que se rigen las relaciones entre Estados. Introduce un sistema de detección precoz de problemas en los sistemas nacionales de asilo o acogida y aborda sus causas profundas antes de que estallen en forma de crisis

comunes para la concesión o la retirada de la protección internacional (refundición) (aplicable desde el 21 de julio de 2015).

${ }^{30}$ Directiva 2003/9/CE del Consejo, de 27 de enero de 2003, por la que se aprueban normas mínimas para la acogida de los solicitantes de asilo en los Estados miembros. Modificada por Directiva 2013/33/UE del Parlamento Europeo y del Consejo, de 26 de junio de 2013, por la que se aprueban normas para la acogida de los solicitantes de protección internacional (refundición) (aplicable desde el 21 de julio de 2015).

${ }^{31}$ Directiva 2004/83/CE del Consejo, de 29 de abril de 2004, por la que se establecen normas mínimas relativas a los requisitos para el reconocimiento y el estatuto de nacionales de terceros países o apátridas como refugiados o personas que necesitan otro tipo de protección internacional y al contenido de la protección concedida. Modificada por Directiva 2011/95/UE del Parlamento Europeo y del Consejo, de 13 de diciembre de 2011, por la que se establecen normas relativas a los requisitos para el reconocimiento de nacionales de terceros países o apátridas como beneficiarios de protección internacional, a un estatuto uniforme para los refugiados o para las personas con derecho a protección subsidiaria y al contenido de la protección concedida (refundición) (aplicable desde el 21 de diciembre de 2013).

${ }^{32}$ Reglamento (CE) n. ${ }^{\circ}$ 343/2003 del Consejo, de 18 de febrero de 2003. Modificado por Reglamento (UE) n. ${ }^{\circ}$ 604/2013 del Parlamento Europeo y del Consejo, de 26 de junio de 2013, por el que se establecen los criterios y mecanismos de determinación del Estado miembro responsable del examen de una solicitud de protección internacional presentada en uno de los Estados miembros por un nacional de un tercer país o un apátrida (refundición) (aplicable desde el 1 de enero de 2014). 
- El Reglamento Eurodac revisado ${ }^{33}$ proporcionará a los cuerpos de seguridad acceso a la base de datos de impresiones dactilares de solicitantes de asilo en circunstancias estrictamente limitadas y con el fin de prevenir, detectar o investigar los delitos más graves como los de asesinato o terrorismo.

La modificación de la legislación europea de asilo ha sido adoptada tras un proceso de negociación largo y complejo. El Tratado de Funcionamiento de la Unión Europea (TFUE) exige a la Unión que adopte medidas sobre asilo de acuerdo con la Convención de 1951 sobre el Estatuto de los Refugiados que contemplen, entre otras cuestiones, un estatuto uniforme de asilo válido en toda la Unión, un estatuto uniforme de protección subsidiaria y procedimientos comunes para la concesión y retirada de dichos estatutos.

La legislación modificada tiene potencial para contribuir de manera sustancial a la armonización de los sistemas de asilo de la Unión. Si se incorporan correctamente a la legislación nacional y se aplican de acuerdo con los principios que gobiernan el SECA, la legislación refundida podría dar lugar a una adecuada identificación y reconocimiento de las personas en necesidad de protección internacional.

Una de las consecuencias del desarrollo del yihadismo y de las crisis humanitarias que se están produciendo, entre otros, en Estados como Siria, Líbano o Irak, ha sido el gran desplazamiento de población que huye de la guerra y busca asilo y protección en la UE, y la UE no ha estado a la altura de las circunstancias. En lo que va de año, más de medio millón de solicitantes de asilo han entrado en Italia, Grecia y Hungría por tierra y por mar. Había, y hay, consenso en que los tres Estados no pueden hacer frente al desafío económico, demográfico y político, puesto que estamos ante el que puede ser el peor momento de desplazados desde la Segunda Guerra Mundial. Es nece-

${ }^{33}$ Reglamento (CE) n. ${ }^{\circ}$ 2725/2000 del Consejo, de 11 de diciembre de 2000, relativo a la creación del sistema «Eurodac» para la comparación de las impresiones dactilares para la aplicación efectiva del Convenio de Dublín. Modificado por Reglamento (UE) n. ${ }^{\circ}$ 603/2013 del Parlamento Europeo y del Consejo, de 26 de junio de 2013 , relativo a la creación del sistema «Eurodac» para la comparación de las impresiones dactilares para la aplicación efectiva del Reglamento (UE) n. ${ }^{\circ}$ 604/2013, por el que se establecen los criterios y mecanismos de determinación del Estado miembro responsable del examen de una solicitud de protección internacional presentada en uno de los Estados miembros por un nacional de un tercer país o un apátrida, y a las solicitudes de comparación con los datos de Eurodac presentadas por los servicios de seguridad de los Estados miembros y Europol a efectos de aplicación de la ley, y por el que se modifica el Reglamento (UE) n. ${ }^{\circ} 1077 / 2011$, por el que se crea una Agencia europea para la gestión operativa de sistemas informáticos de gran magnitud en el espacio de libertad, seguridad y justicia (refundición) (aplicable desde el 20 de Julio de 2015). 
sario actuar. Pero la UE no ha sido capaz de actuar adecuadamente, y se ha visto, por un lado desbordada en el tratamiento de los refugiados, y por otro, han aflorado las disensiones en el seno de la UE. Alemania, Suecia, España, los Estados receptores y Francia, están a favor del mecanismo de reparto de las cuotas, y están aceptando, o van a aceptar, a todos los refugiados pedidos por la Comisión Europea. Del otro lado, Hungría, República Checa y Eslovaquia, sobre todo, han bloqueado el desarrollo de una política de asilo adecuada a los principios europeos ${ }^{34}$.

La ley internacional dice que todo refugiado -que genuinamente lo sea- que llegue a territorio europeo tiene derecho a que se le conceda asilo ${ }^{35}$.

Los estándares de protección difieren considerablemente entre países en Europa. Mientras que en algunos existen marcos legales muy avanzados, en otros los sistemas de protección y asilo aún se encuentran en fase de desarrollo. La adopción en junio de 2013 de unas leyes actualizadas sobre el derecho de asilo de acuerdo con el del Sistema Europeo Común de Asilo (SECA) ha supuesto un avance importante en materia de protección de los refugiados. El SECA establece unos estándares comunes para los Estados Miembros de la Unión Europea (UE).

Sin embargo, es preciso poner de manifiesto la fragilidad de los sistemas de asilo de la UE. Las dificultades para acceder al territorio y completar los procedimientos de asilo, las violaciones del principio de

${ }^{34}$ Las demandas de asilo en la Unión Europea siguen aumentando, resultado de los conflictos y la inestabilidad que se vive en Siria, Irak o el norte de África. Entre julio y septiembre los estados miembros recibieron un total de 413.815 solicitudes, casi el doble de las 213.000 registradas en el trimestre anterior y un dato que esconde realidades muy distintas. Mientras países como Finlandia han visto multiplicarse más de un $800 \%$ las peticiones otros, como España, recibieron menos demandas. Datos facilitados por Eurostat, en fecha 10 de diciembre de 2015.

${ }^{35}$ El Artículo 14 de la Declaración Universal de Derechos Humanos de 1948 dispone que:

1. En caso de persecución, toda persona tiene derecho a buscar asilo, y a disfrutar de él, en cualquier país.

2. Este derecho no podrá ser invocado contra una acción judicial realmente originada por delitos comunes o por actos opuestos a los propósitos y principios de las Naciones Unidas.

También la Carta de los Derechos Fundamentales de la Unión Europea (promulgada en 2007 y de entrada en vigor el 1 de diciembre de 2009), en su artículo 18 garantiza este derecho: Se garantiza el derecho de asilo dentro del respeto de las normas de la Convención de Ginebra de 28 de julio de 1951 y del Protocolo de 31 de enero de 1967 sobre el Estatuto de los Refugiados y de conformidad con la Constitución. 
no devolución, los bajos índices de reconocimiento y la destitución de aquellos que ya habían sido reconocidos como refugiados, siguen justificando la continua puesta en práctica de nuevas políticas.

La centralidad de la crisis de refugiados se debe a que Europa se juega nada más y nada menos que ser fiel a sus valores fundadores. $\mathrm{O}$ la UE es capaz de dar una respuesta eficaz y solidaria a la llegada de los refugiados o no será lo que siempre ha pretendido ser y lo que el resto del mundo piensa que es: una potencia civil, humanitaria; un territorio que fue capaz de convertir la violencia más terrible entre vecinos en un hermoso experimento de paz en donde el respeto a los derechos humanos es el cauce por el que transcurre nuestra convivencia.

Los hechos recientes han puesto de manifiesto que hasta la fecha, la legislación de la UE sobre asilo no ha sido aplicada de manera coherente en el conjunto de la Unión. Esta diferente práctica estatal puede atribuirse, cuando menos, a la existencia de disposiciones de carácter opcional, poco claras, que permiten excesiva discrecionalidad a los Estados miembros. La legislación refundida debería mejorar esta situación, restringiendo el alcance de algunos preceptos de carácter opcional, aclarando ciertas reglas y reforzando los mecanismos de supervisión o monitoreo.

La diversidad de legislaciones nacionales y de sistemas de asilo en la Unión Europea (UE) cuestionan el objetivo común de garantizar condiciones de vida dignas e igualitarias a los refugiados que llegan al Viejo Continente. Derechos básicos como la salud, la educación o el trabajo están claramente en entredicho. Las limitaciones y restricciones impuestas convierten a los solicitantes de asilo en ciudadanos de segunda.

Las Directivas de la Unión Europea que acaban de entrar en vigor, junto con la de Procedimientos de Asilo, recogen las normas sobre las condiciones de acogida que deben cumplir y vinculan a los Estados miembros respecto a las personas que se han visto obligadas a escapar de sus países huyendo de la guerra y de la persecución, y han solicitado protección internacional, y esta normativa establece que los Estados miembros deberán velar por que las condiciones materiales de acogida proporcionen a los solicitantes un nivel de vida adecuado para garantizar su subsistencia y la protección de su salud física y psíquica, con especial atención a grupos vulnerables.

La actual crisis de refugiados e inmigrantes sólo se puede gestionar con una respuesta de emergencia común por parte de Europa. Las medidas que cada país tome de forma individual no resolverán el problema sino que agravarán una situación ya de por sí caótica, au- 
mentando el sufrimiento de las personas y la tensión entre los Estados en un momento en el que Europa necesita más solidaridad y confianza.

Las medidas restrictivas recientemente adoptadas por algunos Estados, especialmente Hungría, y la forma en que están siendo implementadas, que están limitando extraordinariamente el acceso de los refugiados en la frontera, que incluye medidas disuasorias, contravendrían el derecho internacional y la jurisprudencia europea.

Según datos de ACNUR, más de cincuenta millones de personas, la cifra más alta desde la Segunda Guerra Mundial, están desplazadas por culpa de los conflictos armados- la mitad de ellos son niños-. Se estima que más de 400.000 personas han cruzado el Mediterráneo, más de 130.000 sólo en el mes de agosto. De ellos, los sirios representan el 54\% de los refugiados que han cruzado el mar; los afganos son el 14\% y los eritreos el $7 \%$.

Durante un tiempo inicial, la UE desarrolló un papel importante, y brillante, en la crisis de asilo y refugio: Grecia, a pesar de la profunda crisis económica en que se encuentra inmersa, ha acogido a miles de personas diarias, que han desbordado sus puertos y costas, y Alemania asumió en un primer momento un papel histórico en matera de solidaridad, con lo que se han sumado a Italia, que ha asumido un papel fundamental en el proceso de rescate y salvamento en el Mediterráneo. También la Comisión y el Parlamento exigieron una respuesta europea, basada en los principios y valores europeos ${ }^{36}$.

Sin embargo, en los últimos momentos se ha observado una profunda modificación de la política comunitaria en materia de inmigración, pero sobre todo de asilo y refugio. Con el objeto de agilizar las reubicaciones, y evitar las selecciones «a la carta» del destino europeo, la UE ha anunciado que ampliará los centros de control para insistir en el registro de los demandantes de asilo bajo la premisa de que sin registro no hay derecho al asilo.

En el Consejo de Interior celebrado el 9 de noviembre de 2015, se ha indicado cómo el derecho comunitario contempla la posibilidad de detener a aquellos inmigrantes irregulares, o incluso a los refugiados

${ }^{36}$ Más de un millón de migrantes irregulares y refugiados han llegado a Europa por tierra y por mar en el año 2015. La mayoría de ellos, más de 850.000 entraron por Grecia desde Turquía. Una de cada dos personas que utilizaron esta vía de entrada eran refugiados sirios que huyen del conflicto armado; el 20\% ciudadanos afganos. En 2015, más de 3.600 personas murieron tratando de alcanzar Europa. Datos ofrecidos por la Organización Internacional de Migraciones (OIM) y la Agencia de la ONU para los refugiados (ACNUR). 
que no quieran participar en el proceso de registro, detención que podría durar desde los seis meses hasta el año y medio, según los Estados, en virtud de normativa comunitaria. En el Consejo se ha puesto de manifiesto, por un lado, la necesidad de modificar el proceso de registro, evitando la libre elección del asilado o refugiado (la mayoría de los refugiados sigue prefiriendo optar por Alemania o Suecia, Estados que tienen un programa más generoso de acogida). Además de la reubicación -Estados como Finlandia, Luxemburgo, Francia o España, ya han comenzado a acoger a los primeros refugiados, aunque a un ritmo muy lento- la protección de las fronteras ha sido otro de los temas claves, poniendo de manifiesto la política de control de fronteras que define a la política migratoria europea. En este último contexto, se ha adoptado la necesidad de reforzar FRONTEX, e incluso la Comisión ha presentado una propuesta para crear una guardia de frontera antes del final del año de 2015.

Las diferencias comunitarias en materia migratoria se han evidenciado también recientemente. Gran Bretaña, que se replantea la pertenencia a la UE, ha propuesto, como requisitos de renegociación, el reforzamiento de la soberanía nacional y la disminución de derechos, incluso para los inmigrantes comunitarios. Como ha indicado el Primer Ministro británico, la libertad de movimientos nunca ha sido un derecho incondicional, y en estos momentos se exige operar de una manera más sostenible, y para ello, solicita que los ciudadanos de la UE que quieran residir en el Reino Unido estén obligados a trabajar y pagar impuestos durante al menos cuatro años.

Se alega, además de problemas estructurales y económicos, la amenaza a la seguridad, que ha crecido en los últimos años, desde la invasión rusa a Ucrania oriental, al surgimiento del Estado Islámico y la crisis migratoria desatada por la guerra de Siria.

Incluso Alemania ha anunciado un giro a su política de refugiados, al indicar que podría revertir su actual política de acogida a los refugiados, e incluso ejecutar las directivas de Dublín que obligan a solicitar asilo en el primer país de la UE al que lleguen.

La Cumbre sobre Migración celebrada en Malta los días 11 y 12 de noviembre de 2015 se ha planteado el objetivo final de contener los problemas económicos y de seguridad que provocan los flujos migratorios actuales, en especial el desplazamiento de asilados y refugiados, intentando favorecer las relaciones con África, aunque en la idea de que «la libertad de movimientos en la UE» es una línea roja. Se intenta en esta Cumbre que Turquía reduzca la cantidad de personas que atraviesan sus fronteras con Grecia, y, a la vez, dar ayu- 
das económicas a los estados africanos para contener la inmigración y el flujo de asilados.

No obstante, varios Estados europeos, además de los ya indicados, anuncian el endurecimiento de su política migratoria. Suecia ha anunciado que restablecerá los controles fronterizos, mientras que Eslovenia ha comenzado a levantar una valla a lo largo del río Sutla, frontera natural con Croacia, en términos similares a la decisión ya adoptada por el gobierno húngaro, que hizo cambiar la corriente migratoria hacia Eslovenia.

La Cumbre de la Valeta ha consumado la política de cierre de fronteras. Se ha sustituido la idea de cómo ayudar a los refugiados por cómo evitar que lleguen más; sustituir la idea de favorecer la seguridad de los refugiados por la nuestra; se cambia la protección del derecho a la vida o el reconocimiento del derecho de asilo, por nuestro derecho a tener fronteras seguras. Ya no se trata de cómo integrar a los inmigrantes, refugiados o asilados, sino cómo devolverlos a sus países de origen ${ }^{37}$.

En lugar de poner la política exterior y la política de desarrollo al servicio de los fines que son propios a la UE, se adopta una política de fronteras, y el predominio de la seguridad general, y particular de cada uno de los Estados europeos ${ }^{38}$. Esta política se ha visto incrementada a partir de los atentados yihadistas contra Francia del 13 de noviembre.

No obstante entendemos que muros y fronteras no son la solución, y la apelación al miedo, a la seguridad y al bienestar de unos frente al derecho a la vida de otros, tampoco es la solución.

Nuevos acontecimientos han venido a incidir, de nuevo, en la política de la UE ante el terrorismo. Estado Islámico ha exportado al corazón de Europa los métodos más inhumanos para extender el terror ${ }^{39}$.

La inestabilidad en África y Oriente Próximo ha incidido en Europa de dos maneras: como una crisis de asilo y refugio de una magnitud desconocida hasta el momento, y con una amenaza terrorista sin pre-

${ }^{37}$ Vid. José Ignacio-Torreblanca. «Cierre», El País, sábado 14 de noviembre de 2015.

${ }^{38}$ Decisión (UE) 2015/1817 del Consejo de 6 de octubre de 2015 sobre la posición que se ha de adoptar en nombre de la Unión Europea en el sexagésimo sexto período de sesiones del Comité Ejecutivo del Programa del Alto Comisionado de las Naciones Unidas para los Refugiados.

${ }^{39}$ El viernes 13 de noviembre se produjeron en París seis ataques casi simultáneos: cuatro tiroteos, un ataque con explosivos cerca del Estadio de Francia y una toma de rehenes en una sala de conciertos, cuya autoría ha sido reivindicada por ISIS, que han provocado 130 muertos y 352 heridos. 
cedentes, que exige construir una respuesta efectiva que pase, una vez constatados los errores cometidos en la política europea, por dar asilo y refugio a los perseguidos por ISIS, y mejorar los servicios de inteligencia y los medios policiales y judiciales, sin olvidar la activación de la diplomacia para forzar una negociación, y hostigar al EI con medidas financieras y de suministro, y también militares.

Los ataques de París también han afectado de lleno contra el difícil proceso de acogida de refugiados en Europa, y ha dado alas a los Estados reacios a recibir a los peticionarios de asilo y refugio, sembrando el miedo en el resto. El Estado más interesado en establecer un nexo entre terroristas y refugiados ha sido Hungría, cuyo Parlamento ha aprobado, con fecha 17 de noviembre, una ley que permite recurrir ante el Tribunal Europeo de Justicia la decisión comunitaria del programa de reparto de extranjeros, a pesar de que, hasta el momento, FRONTEX ha descartado la hipótesis de que existan indicios de que los yihadistas utilicen las rutas hacia Europa que emprenden los demandantes de asilo.

Ha sido, sin duda, en materia de control de fronteras, donde los atentados han tenido mayores consecuencias.

El Consejo de los Ministros de Justicia e Interior de 20 de noviembre de 2015 ha acordado una serie de medidas que afectan de manera directa a uno de los pilares de la UE. La medida estrella es la revisión de Schengen: al objeto de blindar las fronteras de la UE, la Comisión Europea retocará el código que regula la libre circulación de personas en la Unión para hacer obligatorios los «controles sistemáticos» en sus fronteras exteriores, e interiores, de manera que se revisará toda la documentación y los datos obtenidos se cotejarán con las bases de datos de interpol y la base europea SIS II. También se ha activado un registro sistemático que incluya la toma de impresiones dactilares de los nacionales de terceros países que entren ilegalmente en Schengen, ya sean migrantes o solicitantes de protección internacional, y se realizarán controles sistemáticos en puntos críticos de la geografía europea. Finalmente, se ha aprobado también la creación inmediata del PNR, registro de nombre de pasajeros, que almacenará los datos de los vuelos al menos un año. Sin embargo, esta medida, que levanta muchos recelos como consecuencia de la protección de datos personales y su incidencia en la libertad, tiene que ser aprobada por el Parlamento Europeo, y la Eurocámara no ha logrado avances concluyentes en todo el tiempo en que se viene debatiendo esta medida.

Para el control de la inmigración, en especial para impedir, o ralentizar la marea de refugiados, la UE ha adoptado una serie de me- 
didas para Turquía, país imprescindible para intentar solucionar la crisis de refugiados. Las medidas aprobadas a finales de noviembre de 2015 incluyen 3000 millones de euros, »inicialmente», a cambio de colaboración; la posibilidad de que los turcos no necesiten visado para entrar en la UE en octubre de 2016 -un año antes de lo previsto inicialmente-, y la reapertura de las negociaciones de adhesión ${ }^{40}$. A cambio de estas ventajas, Turquía debe de comprometerse a mejorar la situación socioeconómica de los inmigrantes que alberga; deberá luchar contra las mafias de traficantes de personas que usan los puertos del país para fletar grandes barcos, y, sobre todo, tendrá que controlar sus fronteras, impedir la entrada de inmigrantes irregulares, devolver a los inmigrantes económicos, y deberá readmitir y hacerse cargo de los inmigrantes que se demuestre que han entrado en Europa a través de sus fronteras ${ }^{41}$.

Definitivamente se ha aprobado la aplicación del Registro de Nombres de pasajeros (PNR), también en los vuelos intracomunitarios, como mecanismo en el que los Estados miembros podrán compartir información de cada viajero, sospechoso o no, en los registros policiales como forma preventiva para detectar a presuntos terroristas, y cuyos datos se guardarán durante seis meses ${ }^{42}$.

La UE ha aplazado prolongar de seis meses a dos años la posibilidad de reintroducir controles temporales en sus fronteras internas -la eliminación de Schengen-, aunque ello dependerá de cómo evolucione la crisis de refugiados, y ha conseguido que Grecia cediera parte de soberanía en el control de sus fronteras, ante la amenaza de dejar al país fuera de Schengen, pero, también en materia de control de fronteras, la Comisión quiere crear un «cuerpo de policías de fronteras», que podría actuar, en situaciones de emergencia, aun

${ }^{40}$ Turquía y la UE firmaron su primer acuerdo de asociación hace 50 años. Tras varios intentos fallidos, Ankara consiguió el estatus de candidato a la adhesión en 2004, aunque, desde esa fecha, la UE no ha dejado de dar largas, debido, principalmente a las dificultades del país para asimilar los estándares occidentales en derechos civiles, y los contenciosos que históricamente tiene con Gracia y Chipre.

${ }^{41}$ Decisión de la Comisión, de 24 de noviembre de 2015, sobre la coordinación de las acciones de la Unión y de los Estados miembros mediante un mecanismo de coordinación, el Mecanismo para Turquía en favor de los refugiados.

${ }^{42}$ Directiva (UE) 2015/2302 del Parlamento Europeo y del Consejo, de 25 de noviembre de 2015, relativa a los viajes combinados y a los servicios de viaje vinculados, por la que se modifican el Reglamento (CE) núm. 2006/2004 y la Directiva 2011/83/ UE del Parlamento Europeo y del Consejo y por la que se deroga la Directiva 90/314/ CEE del Consejo. Fecha de transposición: El 01.01.2018, los Estados miembros deben adoptar y publicar las disposiciones legales, reglamentarias y administrativas necesarias para dar cumplimiento a lo establecido en Directiva, disposiciones que se aplicarán a partir del 01.07.2018 (art. 28). 
cuando no fuera solicitado por el Estado que se muestra ineficaz en el control de sus fronteras.

Bruselas quiere transformar FRONTEX, como órgano de coordinación en el control de fronteras, en una especie de Agencia Europea de Guardias de Fronteras, dotándola de numerosos agentes que puedan ser movilizados por la UE para aliviar las crisis fronterizas -hasta quince países europeos limitan por tierra o por mar con un país ajeno a Schengen-.

A pesar de que esta medida puede chocar con el hecho de que buena parte de los inmigrantes sean refugiados, que tienen derecho a ser acogidos al menos mientras se decide sobre su estatus, por lo que resulta difícil reducir su tránsito hacia la UE, lo cierto es que las medidas que está abordando la UE, que se mueve de manera imprecisa, precipitada y a golpe de efectos, tienen como objetivo común la limitación de derechos a los inmigrantes y refugiados y el aumento de cesión de soberanía por parte de los Estados, en detrimento de una verdadera política exterior de la UE.

A las políticas restrictivas de Hungría, que construyó una vaya con Serbia, con Croacia y con Rumanía, ignorando el acuerdo Schengen, y ha aprobado penas de cárcel de hasta tres años para la aquellos que intenten entrar irregularmente en el país, se han sumado otras. El parlamento danés aprobó el 26 de enero un proyecto de ley que incluye limitar la reagrupación familiar en el país, el endurecimiento de los criterios para obtener un permiso de residencia, y la confiscación de dinero y objetos de valor a los refugiados para costear su estancia, medidas que se unen a la posibilidad de detención policial a inmigrantes y solicitantes de asilo sin control judicial, aprobada en noviembre de 2016. También Suiza exige a los refugiados que entreguen al Estado los activos que tengan un valor superior a mil francos suizos, medida que también se aplica en los estados federados alemanes de Babiera y Bade-Württemberg. En Alemania, se ha adoptado un acuerdo entre los partidos gobernantes para endurecer el derecho de asilo, dificultar la reagrupación familiar y acelerar las expulsiones.

Se han adoptado medidas excéntricas, y tan polémicas que se han tenido que retirar, en ciudades de Reino Unido: en Cardiff, los solicitantes de asilo eran obligados a lucir pulseras identificativas; y en Middlesbrough, las puertas de las casas donde habitaban refugiados eran pintadas de rojo.

Además, los controles aduaneros temporales se han extendido por toda Europa, y se han adoptado restricciones y medidas discriminatorias en las políticas fronterizas y de asilo en Austria, Eslovenia y Mace- 
donia. En algunos casos, se han escuchado afirmaciones xenófobas en contra de la inmigración musulmana, como en Bulgaria, República Checa o Eslovaquia. Y Alemania y Turquía han solicitado la intervención de la OTAN para frenar la entrada de refugiados a Europa.

Deportaciones masivas, vallas y alambradas, encarcelamientos, confiscaciones, o el establecimiento de elementos distintivos, además de limitar derechos humanos, son medidas que tienen un efecto devastador sobre personas y grupos vulnerables, tanto en aspectos económicos, como familiares, sociales y de solidaridad ${ }^{43}$.

${ }^{43}$ Estas actuaciones se producen en un contexto social en el que, en enero de 2016, 67.000 personas huyen de sus países, 40 veces más que en enero de 2015, según datos de FRONTEX. De los 160.000 refugiados a los que en 2015 se pactó reubicar en dos años, solo 500 lo han conseguido hasta el momento (datos de ACNUR), y en 2015 ha habido más de un millón de desplazamientos en busca de asilo y refugio a Europa, según datos que ofrece la Comisión Europea. 